\title{
Optical and Photovoltaic Properties of Thieno[3,2-b]thiophene- Based Push-Pull Organic Dyes with Different Anchoring Groups for Dye-Sensitized Solar Cells
}

\author{
Sara S. M. Fernandes, ${ }^{\dagger}$ M. Cidália R. Castro, ${ }^{\dagger, \|}$ Ana Isabel Pereira, ${ }^{\ddagger}$ Adélio Mendes, ${ }^{\ddagger}$ Carlos Serpa, ${ }^{\S}$
} João Pina, ${ }^{*}{ }^{\S}$ Licínia L. G. Justino, ${ }^{\S \odot}$ Hugh D. Burrows, ${ }^{\S}$ and M. Manuela M. Raposo ${ }^{*}{ }^{\dagger} \odot$

${ }^{\dagger}$ Centro de Química, Universidade do Minho, Campus de Gualtar, 4710-057 Braga, Portugal

${ }^{\ddagger}$ LEPABE-Faculdade de Engenharia, Universidade do Porto, rua Dr. Roberto Frias, 4200-465 Porto, Portugal

${ }^{\S}$ Centro de Química de Coimbra, Departamento de Química, Universidade de Coimbra, P3004-535 Coimbra, Portugal

Supporting Information

\begin{abstract}
The effect of anchoring groups on the optical and electrochemical properties of triphenylamine-thienothiophenes, and on the photovoltaic performance of DSSCs photosensitized with the prepared dyes, was studied using newly synthesized compounds with cyanoacetic acid or rhodanine-3-acetic acid groups. Precursor aldehydes were synthesized through Suzuki cross-coupling, whereas Knoevenagel condensation of these with 2-cyanoacetic acid or rhodanine-3-acetic acid afforded the final push-pull dyes. A comprehensive photophysical study was performed in solution and in the solid state. The femtosecond time-resolved transient absorption spectra for the synthesized dyes were obtained following photoexcitation in solution and for the dyes adsorbed to $\mathrm{TiO}_{2}$ mesoporous films. Information on conformation, electronic structure, and electron distribution was obtained by density functional theory (DFT) and time-dependent DFT calculations. Triphenylamine-thienothiophene functionalized with a cyanoacetic acid

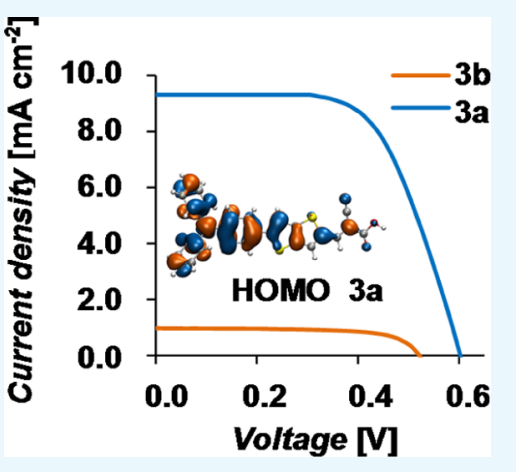
anchoring group displayed the highest conversion efficiency (3.68\%) as the dye sensitizer in nanocrystalline $\mathrm{TiO}_{2}$ solar cells. Coadsorption studies were performed for this dye with the ruthenium-based N719 dye, and they showed dye power conversion efficiencies enhanced by $20-64 \%$. The best cell performance obtained with the coadsorbed N719 and cyanoacetic dye showed an efficiency of $6.05 \%$.
\end{abstract}

\section{INTRODUCTION}

Dye-sensitized solar cells (DSSCs) involving sensitizers adsorbed onto nanocrystalline $\mathrm{TiO}_{2}$ electrodes are of major interest because of their high incident solar light-to-electricity conversion efficiency, low cost, low maintenance, and high stability. Extensive research in this area has resulted in the development of cells with efficiencies of ca. 13\%, achieved by using polypyridylruthenium- or Zn-porphyrin-based dyes. ${ }^{1-8}$

Metal-free organic dyes have great advantages over $\mathrm{Ru}$ or $\mathrm{Zn}$ complexes as sensitizers because of their high molar extinction coefficient, simple and low cost synthesis and purification, and diverse possibilities for tuning the photophysical and electrochemical properties through structural modifications. ${ }^{9-22}$ Although organic DSSCs initially showed low performances compared with metal complex-based ones, recent works report efficiencies, which approach or surpass those of $\mathrm{Ru}$ complexes $(12 \%) ;^{23-36}$ actually, an efficiency of $14 \%^{37}$ was reported using cosensitization between two organic dyes bearing different anchoring groups (alkoxysilyl and carboxy moieties). However, despite the disadvantages of low abundance in nature and/or latent risk to the environment of metals such as ruthenium, the high efficiency and stability of transition metal complexes still make them major players in DSSC development. In addition, $\mathrm{Ru}(\mathrm{II})$ complexes have desirable spectral and photophysical properties, such as intense metal-to-ligand charge-transfer transition in the visible region, whereas organic dyes still show limitations, including narrow absorption bands, aggregation, poor absorption in the red and infrared regions, and poor stability. ${ }^{6,38,39}$

A variety of organic dyes have been studied as sensitizers, the general structure of which involve a donor $-\pi$-spacer-acceptor push-pull system, which favors electron injection through an efficient charge transfer and separation on photoexcitation, and allows possibilities of a wide range of structural modifications to the donor, $\pi$-bridge, acceptor group, and anchoring moiety. The tuning of the donor moiety can improve interfacial phenomena, spectral properties, and electronic energy levels, whereas the conjugation between the donor and the $\pi$-bridge can be used to determine the efficiency of charge separation. $^{\text {9-22,34,40,41 }}$

Common electron-donor groups, including diphenylamine, $^{26,27}$ carbazole, $^{42}$ indoline, ${ }^{10,26}$ and triphenylamine ${ }^{43}$ in particular, are extensively used in organic photovoltaics as an excellent electron source, offering extensive possibilities for

Received: August 16, 2017

Accepted: December 4, 2017

Published: December 29, 2017 
Scheme 1. Reagents and Conditions: (a) 1,2-Dimethoxyethane, $\mathrm{Pd}\left(\mathrm{PPh}_{3}\right)_{4}, \mathrm{~N}_{2}, \mathrm{EtOH}$, and $\mathrm{Na}_{2} \mathrm{CO}_{3}$; (b) 2-Cyanoacetic Acid, Piperidine, and EtOH; (c) Rhodanine-3-acetic Acid, Piperidine, and EtOH

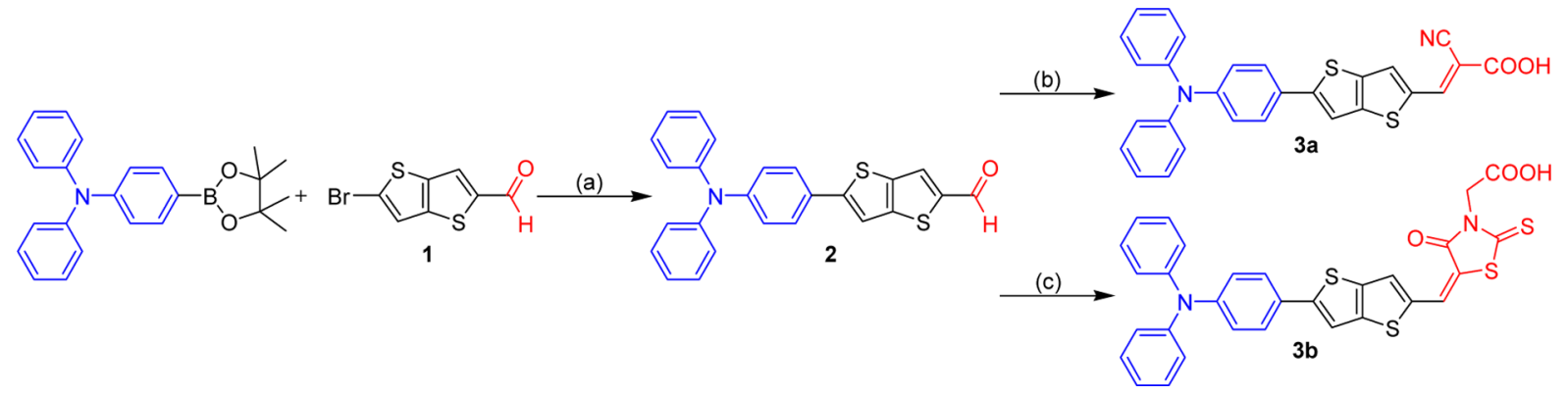

modifying the structure, function, light harvesting, energy levels, charge generation, and separation. Additionally, they have nonplanar structures that minimize aggregation and display high conversion efficiencies in DSSCs. $25,44-49$ The conjugation path usually involves thiophene, ${ }^{9-22,27,50,51}$ ethene, ethyne, $^{52,53}$ or benzene units. ${ }^{54,55}$ Because of their excellent charge-transport properties, the most efficient systems for DSSCs frequently contain thiophene units, ${ }^{9-22,31,34,36,50,51}$ such as oligothiophenes, fused thiophenes, or alkylenedioxythiophenes. The fused ring thienothiophene moiety offers even better $\pi$-conjugation and smaller geometric relaxation energy losses upon oxidation than bithiophene. ${ }^{50,51}$

The acceptor groups strongly influence the photovoltaic properties of the DSSC as they are key to electron injection from the dye molecule to the conduction band ( $\mathrm{CB}$ ) of the semiconductor film; they are also responsible for anchoring the sensitizing dye to the surface of the semiconductor. The most common anchoring group involves the carboxylic acid $(-\mathrm{COOH})$ because of its relative stability, ease of synthesis, strong binding, and good electron communication between the dye and the surface, forming an ester linkage with $\mathrm{TiO}_{2}$. This group is normally used in the form of cyanoacetic acid, although derivatives, such as rhodanine-3-acetic acid, esters, acid chlorides, phosphonic acids, or acetic anhydride, have also been studied, albeit with lower efficiencies. ${ }^{9-22,25,56,57}$

We report the synthesis and evaluation of the optical and electrochemical properties of two heterocyclic organic dyes, which contain thieno[3,2- $b]$ thiophene as the $\pi$-bridge, a triphenylamine moiety as the electron donor group, and cyanoacetic acid, $3 \mathbf{a}$, or rhodanine-3-acetic acid, $\mathbf{3 b}$, as acceptor/anchoring moieties. The photovoltaic performance of DSSCs photosensitized with the prepared dyes $\mathbf{3} \mathbf{a}-\mathbf{b}$ was also studied. This comprehensive experimental analysis, combined with theoretical studies based on density functional theory (DFT) calculations, is used to evaluate the effect of two different anchoring groups on the performance of the DSSCs.

\section{RESULTS AND DISCUSSION}

2.1. Synthesis and Characterization. The structures of the push-pull dyes $\mathbf{3 a}-\mathbf{b}$ and the synthetic protocols followed are depicted schematically in Scheme 1 . The dyes are based on a thieno[3,2-b] thiophene $\pi$-spacer, which exhibits good chargetransfer properties, excellent $\pi$-conjugation, and low geometric relaxation energy upon oxidation. ${ }^{50,51}$ Triphenylamine was chosen as the donor group because of its excellent electrondonating ability, hole-transport properties, and capacity to suppress the aggregation of the dye through its nonplanar structure. $^{25,31,36,44-49}$ Combined theoretical and experimental studies (optical, redox, and photovoltaic) were carried out to determine the most efficient heterocyclic dye as sensitizer for DSSCs.

Compounds $\mathbf{3} \mathbf{a}-\mathbf{b}$ were readily obtained using the two-step protocol shown in Scheme 1. Aldehyde 2 was synthesized in a 95\% yield through a Suzuki-Miyaura coupling of commercially available 4-(diphenylamino)phenylboronic acid pinacol ester with 5-bromothieno[3,2-b] thiophene-2-carbaldehyde 1 . This precursor was synthesized using the same experimental procedure we reported recently. ${ }^{58}$ Knoevenagel condensation of aldehyde 2 with 2 -cyanoacetic acid or rhodanine-3-acetic acid in refluxing ethanol afforded pure dyes $\mathbf{3} \mathbf{a}-\mathbf{b}$ in moderateto-good yields $(55-82 \%)$ (Table $S 1$ in the Supporting Information). The structures of all synthesized heterocycle $\pi$ systems were confirmed by standard spectroscopic and analytical techniques (see the Experimental Section in the Supporting Information for more details).

2.2. Electrochemical Study. The alignment of the highest occupied molecular orbital (HOMO) and lowest unoccupied molecular orbital (LUMO) energy levels relative to the inorganic semiconductor and electrolyte is crucial for the efficient operation of the dye in DSSCs. To guarantee efficient electron injection into the $\mathrm{TiO}_{2} \mathrm{CB}$, the $\mathrm{LUMO}$ level of the dye must be higher in energy than the $\mathrm{TiO}_{2} \mathrm{CB}$ edge, whereas the HOMO level must be lower in energy than the redox potential of the redox couple $\left(3 \mathrm{I}^{-} / \mathrm{I}_{3}^{-}\right)$for efficient regeneration of the oxidized dye.

The oxidation and reduction potentials of dyes $\mathbf{3} \mathbf{a}-\mathbf{b}$ were measured by cyclic voltammetry $(\mathrm{CV})$ to evaluate the redox characteristics of the excited dye molecule relative to the $\mathrm{CB}$ of $\mathrm{TiO}_{2}$ and the possibility of regeneration of oxidized dyes. CV measurements were performed in degassed dimethylformamide (DMF) using $0.1 \mathrm{M}$ tetrabutylammonium tetrafluoroborate as the supporting electrolyte, a glassy carbon working electrode (scan rate $0.1 \mathrm{~V} \mathrm{~s}^{-1}$ ), a $\mathrm{Pt}$ counter electrode, and an $\mathrm{Ag} / \mathrm{AgCl}$ reference electrode; ${ }^{59,60}$ data are summarized in Table 1 .

The HOMO levels of dyes $\mathbf{3} \mathbf{a}$ and $\mathbf{3} \mathbf{b}$ were calculated from the first oxidation potentials $\left(E_{\mathrm{ox}}\right)(-5.07$ and $-5.03 \mathrm{eV}$, respectively). These are less than the energy of the $3 \mathrm{I}^{-} / \mathrm{I}_{3}{ }^{-}$ redox couple $(-4.6 \mathrm{eV})$, indicating that, thermodynamically, the oxidized dyes formed from electron injection into the $\mathrm{CB}$ of $\mathrm{TiO}_{2}$ will favorably accept electrons from $\mathrm{I}^{-}$ions, thus providing ample driving force for effective dye regeneration. The LUMO levels of these dyes are -2.69 and $-2.88 \mathrm{eV}$, which are higher than the $\mathrm{CB}$ of $\mathrm{TiO}_{2}(-4.0 \mathrm{eV})$, indicating that electron injection from the excited molecule to the $\mathrm{CB}$ of $\mathrm{TiO}_{2}$ is energetically favorable. ${ }^{61}$ Electron injection to very high densities of $\mathrm{TiO}_{2}$ acceptor states can involve a very high interfacial electronic coupling process, quite insensitive to high values of $-\Delta G .^{62}$ In agreement with this, injection from the 
Table 1. Electrochemical Data of Dyes $3 a-b$

\begin{tabular}{|c|c|c|c|c|c|c|}
\hline \multirow[b]{2}{*}{ compds } & \multicolumn{2}{|c|}{ reduction $^{a}$} & \multirow{2}{*}{$\frac{\text { oxidation }^{a}}{{ }^{1} E_{\mathrm{pa}}}$} & \multirow[b]{2}{*}{$\begin{array}{c}E_{\text {HOMO }}^{b} \\
{[\mathrm{eV}]}\end{array}$} & \multirow[b]{2}{*}{$\begin{array}{c}E_{\text {LUMO }}{ }^{b} \\
{[\mathrm{eV}]}\end{array}$} & \multirow[b]{2}{*}{$\begin{array}{c}\text { band gap } \\
{[\mathrm{eV}]}\end{array}$} \\
\hline & $\begin{array}{c}-{ }^{1} E_{\mathrm{pc}} \\
{[\mathrm{V}]}\end{array}$ & $\begin{array}{c}-{ }^{2} E_{\mathrm{pc}} \\
{[\mathrm{V}]}\end{array}$ & & & & \\
\hline $3 a$ & 1.70 & 2.14 & 0.68 & -5.07 & -2.69 & 2.38 \\
\hline $3 b$ & 1.51 & 2.47 & 0.64 & -5.03 & -2.88 & 2.15 \\
\hline N719 & 2.04 & 2.52 & 0.46 & -4.85 & -2.35 & 2.50 \\
\hline
\end{tabular}

${ }^{a}$ Measurements made in dry DMF containing $1.0 \mathrm{mM}$ of each compound and $0.1 \mathrm{M}\left[\mathrm{NBu}_{4}\right]\left[\mathrm{BF}_{4}\right]$ as the base electrolyte at a carbon working electrode with a scan rate of $0.1 \mathrm{~V} \mathrm{~s}^{-1}$. All $E$ values are quoted in volts vs the ferrocenium/ferrocene couple. $E_{\mathrm{pc}}$ and $E_{\mathrm{pa}}$ correspond to the cathodic and anodic peak potentials, respectively. ${ }^{b} E_{\text {HOMO }}=$ $-\left(4.39+E_{\mathrm{ox}}\right)(\mathrm{eV})$ and $E_{\text {LUMO }}=-\left(E_{\text {red }}+4.39\right)(\mathrm{eV}) .{ }^{59,60}{ }^{c}$ Calculated from the difference between the onset potentials for oxidation and reduction.

unrelaxed dye excited states has been observed as one of the main electron injection paths. ${ }^{63}$ Generally, a minimum driving force of $0.2 \mathrm{~V}$ is sufficient to ensure fast excited-state injection and regeneration of the oxidized dye. ${ }^{64}$ Therefore, dyes $3 \mathbf{a}-\mathbf{b}$ have sufficient driving force for electron transfer from the excited molecules to the $\mathrm{CB}$ of $\mathrm{TiO}_{2}$ and can be used as sensitizers for possible electron injection in DSSCs.

2.3. Photovoltaic Performance of the DSSCs. The photovoltaic performance parameters (short-circuit current density, $J_{\mathrm{SC}}$; open circuit voltage, $V_{\mathrm{OC}}$; fill factor, $\mathrm{FF}$; and efficiency, $\eta$ ) of DSSCs sensitized with dyes $\mathbf{3} \mathbf{a}-\mathbf{b}$ are presented in Table 2 and Figure S1 and compared with those of the standard ruthenium-based dye N719.

Table 2. Photovoltaic Performance of DSSCs Based on Dyes $3 a, 3 b$, and N719

\begin{tabular}{lcccc} 
dye & $V_{\mathrm{OC}}[\mathrm{V}]$ & $J_{\mathrm{SC}}\left[\mathrm{mA} \mathrm{cm}^{-2}\right]$ & $\mathrm{FF}$ & $\eta[\%]$ \\
3a & 0.600 & 9.52 & 0.632 & 3.68 \\
3b & 0.517 & 0.97 & 0.688 & 0.35 \\
N719 & 0.750 & 15.58 & 0.692 & 8.42 \\
\hline
\end{tabular}

From Table 2 and Figure S1, it is clear that the photovoltaic performances of the DSSCs are affected by the nature of the acceptor groups on the thienothiophene dyes. Comparison of the devices with dyes $\mathbf{3 a}$ and $\mathbf{3 b}$ shows that the photovoltaic performances are significantly improved upon replacing rhodanine-3-acetic acid with cyanoacetic acid, with the power conversion efficiency of the solar cell based on cyanoacetic dye 3a being 10 times higher than that of rhodanine dye $\mathbf{3 b}$. The very low photovoltaic performance exhibited with dye $3 \mathbf{b}$ bearing rhodanine-3-acetic acid as an acceptor/anchoring group $(\eta=0.35 \%)$ could be due to the abated short-circuit current density $\left(0.97 \mathrm{~mA} \mathrm{~cm}{ }^{-2}\right)$. This parameter is related to the interaction between $\mathrm{TiO}_{2}$ and the dye sensitizer, and the lower value observed here can be attributed to the inefficient electron injection from the photoexcited dye into the $\mathrm{CB}$ of $\mathrm{TiO}_{2}$ caused by the LUMO level being centered on the carbonyl and thiocarbonyl groups, and therefore isolated from the $-\mathrm{COOH}$ anchoring group by the methylene linker, ${ }^{57,61,64-68}$ despite its higher energy (relative to dye 3a) and a stronger electron injection driving force. This behavior for organic dyes with rhodanine-3-acetic acid can be attributed to the lack of conjugation between the rhodanine ring and the carboxyl anchoring group. ${ }^{69}$
By contrast, dye 3a shows an efficiency of $3.68 \%$, with a $J_{S C}$ of $9.52 \mathrm{~mA} \mathrm{~cm} \mathrm{~cm}^{-2}$ and $V_{\mathrm{OC}}$ of $0.600 \mathrm{~V}$. This corresponds to ca. $44 \%$ of the power conversion efficiency generated by the reference DSSC using the N719 dye. The significant improvement is due to the replacement of rhodanine-3-acetic acid by cyanoacetic acid as the acceptor/anchoring group, which leads to more effective electron injection into $\mathrm{TiO}_{2}$, partly because cyanoacetic acid presents better coplanarity with the spacer unit and a lower energy HOMO that facilitates dye regeneration by the electrolyte.

Because of the relatively low molar extinction coefficients of the metal-to-ligand charge-transfer band of ruthenium-based dyes $\left(<20000 \mathrm{M}^{-1} \mathrm{~cm}^{-1}\right)$, DSSCs based on them must use thick $\mathrm{TiO}_{2}$ films to obtain maximum efficiencies. By contrast, organic dyes commonly have higher molar extinction coefficients, which allow the use of thinner films and correspondingly reduced charge-transport losses. ${ }^{9-22,32} \mathrm{Un}$ fortunately, they normally display narrow absorption bands, which decrease the light-harvesting ability. ${ }^{11,14,23,39}$ For a better understanding of the differences in the performance between DSSC fabricated with dye $3 a$ (which exhibits the best photovoltaic performance) and the reference DSSC loaded with the N719 dye and the combination of the advantages of the two dye families, coadsorption was performed. Coadsorbing different dyes that cover a different visible spectral region can be an effective and economic way to increase the efficiency of the solar cells and in addition, minimize dye aggregate formation frequently observed on these systems.

The photovoltaic performances of the devices produced by coadsorption are presented in Table 3 . It is worth noting that

Table 3. Photovoltaic Parameters of DSSCs Sensitized with 3a Mixed with N719

\begin{tabular}{lcccc}
\multicolumn{1}{c}{ dye } & $V_{\mathrm{OC}}[\mathrm{V}]$ & $J_{\mathrm{SC}}\left[\mathrm{mA} \mathrm{cm}^{-2}\right]$ & $\mathrm{FF}$ & $\eta[\%]$ \\
3a & 0.600 & 9.52 & 0.632 & 3.68 \\
3a/N719-75/25 & 0.610 & 11.56 & 0.612 & 4.41 \\
3a/N719-50/50 & 0.640 & 13.57 & 0.610 & 5.52 \\
3a/N719-25/75 & & \\
N719 & 0.660 & 14.48 & 0.606 & 6.05 \\
Nolume percent mixture ratios. & 0.750 & 15.58 & 0.692 & 8.42 \\
${ }^{a}$ Volum
\end{tabular}

the short-circuit current density decreases as the volume fraction of dye $3 a$ present in the sensitizing mixture increases (Figure 1a), which can be partially related to the decrease in the absorption of the $\mathbf{N 7 1 9}$ band at $530 \mathrm{~nm}$ (Figure $1 \mathrm{~b}$ ).

The same tendency is observed for the open circuit voltage, meaning that the presence of dye $3 a$ favors back electron transfer between $\mathrm{TiO}_{2}$ and the electrolyte. With the coadsorption of N719, the cell efficiencies were improved by 20-64\%.

2.4. Photophysical Studies. The dye is an essential and unique constituent of DSSCs that works as an antenna through light harvesting. The overlap of its spectral response with the solar spectrum will, to a large extent, affect the device photocurrent. Therefore, the characterization of the electronic spectral and photophysical properties for the dyes is essential and was performed for $\mathbf{3 a}-\mathbf{b}$ in solution and in the solid state.

The absorption and fluorescence emission spectra for pushpull compounds 3 in ethanol solution at room temperature are presented in Figure S2 in the Supporting Information. In general, both absorption and emission spectra are broad and devoid of vibronic structure. The large Stokes shifts found for 

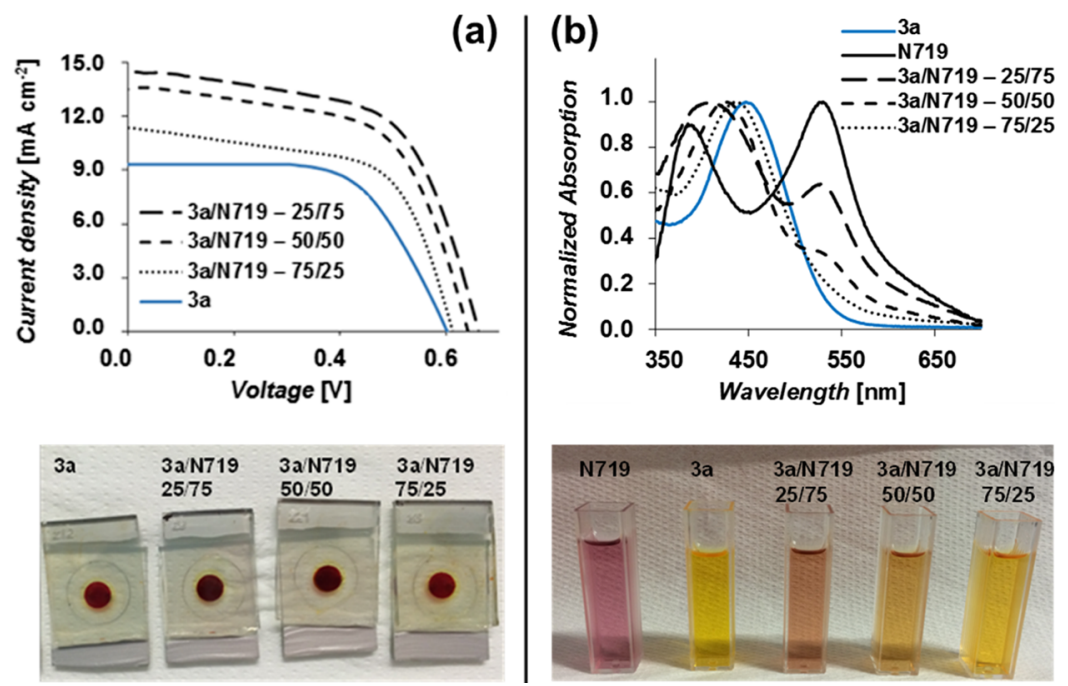

Figure 1. (a) Photocurrent density-voltage spectra of the devices prepared with compound 3a mixed in different volume fractions with the N719 dye and the respective DSSC devices, together with (b) the normalized absorption spectra for 3a mixed with the N719 dye in ethanol solution at $293 \mathrm{~K}$.

Table 4. Transient Lifetimes $\left(\tau_{i}\right)$ Obtained from the SVD/Global Analysis (Using a Sequential Model) of the Ultrafast TimeResolved Transient Absorption Data of the Investigated Compounds in Acetonitrile $\left(\mathrm{CH}_{3} \mathrm{CN}\right)$ and Ethanol Solutions at $293 \mathrm{~K}^{a}$

\begin{tabular}{|c|c|c|c|c|c|c|c|c|c|}
\hline compds & $\lambda_{\mathrm{exc}}[\mathrm{nm}]$ & solvent & $\tau_{1}[\mathrm{ps}]$ & $\tau_{2}[\mathrm{ps}]$ & $\tau_{3}[\mathrm{ps}]$ & $\tau_{4}[\mathrm{ps}]$ & $\left(\tau_{1}\right)[\mathrm{ps}]$ & $\left(\tau_{2}\right)[\mathrm{ps}]$ & $\left(\tau_{3}\right)[\mathrm{ps}]$ \\
\hline \multirow[t]{4}{*}{$3 a$} & 420 & $\mathrm{CH}_{3} \mathrm{CN}$ & 0.36 & & 99 & 1584 & & & \\
\hline & 455 & $\mathrm{CH}_{3} \mathrm{CN}$ & 0.45 & & 119 & 2032 & & 285 & 2067 \\
\hline & 455 & ethanol & 0.80 & 9.8 & 40 & 1056 & & 106 & 1422 \\
\hline & 440 & $\mathrm{TiO}_{2}$ film & & 1.8 & 25 & 2174 & & & \\
\hline \multirow[t]{3}{*}{$3 b$} & 455 & $\mathrm{CH}_{3} \mathrm{CN}$ & 0.29 & & 28 & 600 & & 347 & 1012 \\
\hline & 455 & ethanol & 0.71 & 7.5 & 28 & 316 & 36 & 184 & 509 \\
\hline & 470 & $\mathrm{TiO}_{2}$ film & & 0.32 & 12 & 120 & & & \\
\hline
\end{tabular}

${ }^{a}$ Also presented in parenthesis (for comparison) are the fluorescence decay times for $3 \mathbf{a}\left(\lambda_{\text {exc }}=445 \mathrm{~nm}\right)$ and $3 \mathbf{b}\left(\lambda_{\text {exc }}=451 \mathrm{~nm}\right)$ obtained by TCSPC at $293 \mathrm{~K}$.

them (5718-6305 $\mathrm{cm}^{-1}$, see Table S1) strongly suggest the involvement of an intramolecular charge-transfer process between the donor and acceptor groups.

Rhodanine-3-acetic acid derivative $\mathbf{3 b}$ leads, as expected, to the most pronounced bathochromic shift both in the absorption and emission spectra (Table S1 and Figure S2) because of the greater conjugation of the 4-oxo-2-thioxothiazolidine ring compared with the cyanoacetic group; ${ }^{27,66}$ indeed, 3b displays a $54 \mathrm{~nm}$ (absorption) and $79 \mathrm{~nm}$ (emission) red shift when compared to cyanoacetic acid dye 3a. In addition, a significant decrease in the fluorescence quantum yield was observed on going from $3 \mathbf{a}$ to $3 \mathbf{b}\left(\phi_{\mathrm{F}}=0.36\right.$ for the cyanoacetic acid derivative versus 0.02 for the rhodanine-3-acetic acid, Table S1).

Push-pull compound 3a exhibits a higher molar extinction coefficient (22079 $\mathrm{M}^{-1} \mathrm{~cm}^{-1}$, Table S1) than the standard ruthenium dyes N3 $\left(13900 \mathrm{M}^{-1} \mathrm{~cm}^{-1}\right)^{75}$ and N719 (14000 $\left.\mathrm{M}^{-1} \mathrm{~cm}^{-1}\right){ }^{70}$ which is advantageous for the light-harvesting process. By contrast, rhodanine dye $3 \mathbf{b}$ exhibits a somewhat lower molar extinction coefficient of $12450 \mathrm{M}^{-1} \mathrm{~cm}^{-1}$; see Table S1.

The fluorescence lifetimes of these compounds in acetonitrile and ethanol were also obtained by time-correlated single photon counting (TCSPC, Figure S3 in the Supporting Information). With the exception of $\mathbf{3 b}$ in ethanol (where a triple exponential decay law was necessary), the fluorescence decays were well-fitted with the sum of two exponentials (see
Table 4 and Figure S3 inset with the lifetimes, $\tau_{i}$, and amplitude values, $a_{i}$ ).

2.5. Ultrafast Dynamics Studies. Although it is wellestablished that electron injection from a molecular electron donor to the $\mathrm{CB}$ of $\mathrm{TiO}_{2}$ can be an extremely fast process $(<100 \mathrm{fs})$, the presence of fast competing processes with electron injection directly affects the incident photon-to-current efficiency of photovoltaic cells and concomitantly lowers the conversion efficiencies. ${ }^{71,72}$ Inherently fast deactivation channels need to be avoided to obtain highly efficient electron injection in any excited state. These are competitive processes on timescales ranging from hundreds of femtoseconds to tens of picoseconds, such that a detailed study of the excited-state decay channels of dyes, both in solution and adsorbed onto $\mathrm{TiO}_{2}$, can provide valuable information relevant for the rationalization of DSSC efficiencies.

2.5.1. Femtosecond Transient Absorption (fs TA) Study of $3 a$ and $3 b$ in Acetonitrile $\left(\mathrm{CH}_{3} \mathrm{CN}\right)$ and Ethanol (EtOH) Solutions. The time-resolved transient absorption spectra for the investigated compounds in aerated acetonitrile and ethanol solutions were measured in the $450-800 \mathrm{~nm}$ range and collected within a 7.6 ns time window; see Figure 2. These two solvents were chosen to (i) help us differentiate between the intrinsic ultrafast decay components of the investigated compounds and solvation dynamics and (ii) see how the protic or aprotic character of these solvents will help us study the occurrence and possibly distinguish between deactivation 


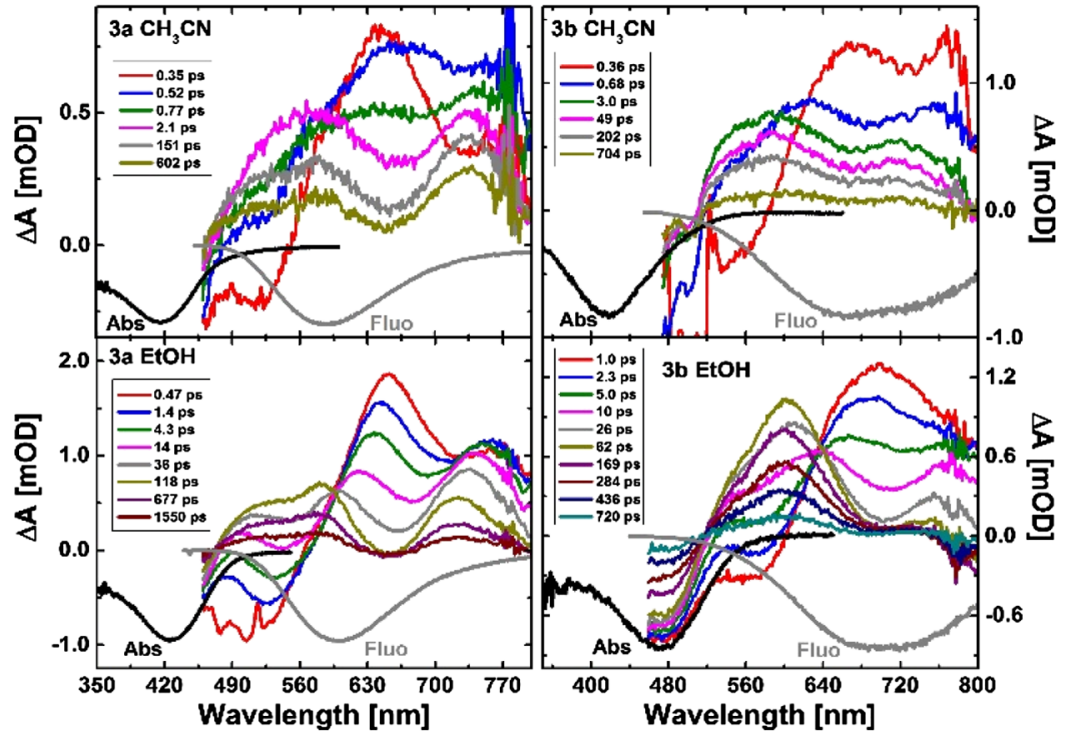

Figure 2. Time-resolved transient absorption data for the investigated samples collected with $\lambda_{\text {exc }}=455 \mathrm{~nm}$ in acetonitrile $\left(\mathrm{CH}_{3} \mathrm{CN}\right)$ and ethanol $(\mathrm{EtOH})$ solutions at $293 \mathrm{~K}$. The spikes on the blue side of the spectra are due to Raman scattering. Also presented for comparison are the normalized and inverted ground-state absorption and fluorescence emission spectra.

processes, such as the excited-state proton transfer (ESPT) and/or structural relaxation in these derivatives. Previously, for $\mathrm{D}-\pi-\mathrm{A}$ molecules with the acceptor groups, cyanoacetic acid and rhodanine, these two specific processes were observed and associated with characteristic lifetimes. ${ }^{72}$ In addition, it was reported that in aprotic and nonpolar solvents, ESPT can occur from one dye molecule's carboxylic acid to another hydrogenbonded molecule (associated by dimerization), whereas in protic solvents, in which dimerization by hydrogen bonding is inhibited, this process can instead involve the molecules of the solvent.

The fs-TA data show that the spectra are dominated by broad transient absorption bands (in the $450-850 \mathrm{~nm}$ range, Figure 2). Also present are the negative ground-state bleach and stimulated emission bands. The latter, due to the strong overlap with the positive excited-state absorption bands, only present small contributions at shorter wavelengths (see Figure 2 and the comparison with the normalized absorption and emission bands).

Global fit analysis (using a sequential model) was performed with singular value decomposition (SVD) to better describe the observed dynamics. In the global analysis, the kinetic traces (at different wavelengths) are fitted using the same (multi)exponential equation, with the same lifetimes for all wavelengths, but with their amplitudes free to vary. Thus, each lifetime has different amplitudes at different wavelengths represented by the decay-associated spectrum for this lifetime. The best-fit results, together with the decay-associated spectra and representative kinetic traces of the characteristic transient absorption data, are presented in Figures S4 and S5 in the Supporting Information and Table 4. In general, in the acetonitrile solvent, three lifetime components were needed to properly fit the kinetic traces, whereas in ethanol, four lifetimes were required to obtain a good fit (Table 4 and Figures S4 and S5). The fast decay component observed in acetonitrile, with values of 0.45 ps (3a) and 0.29 ps (3b), can be assigned to the solvent relaxation of the transient species, whereas the two longer lifetimes correspond to the excited-state decay of the compounds. These fast components are consistent with the solvent relaxation times previously reported for coumarin C153 in acetonitrile, where the characteristic times of 0.12 and 0.26 ps were related to the inertial and diffusional solvation components, respectively. ${ }^{73}$ In our case, in acetonitrile, it was not possible to distinguish between the two solvation components, and only one lifetime was found in the solvation dynamics. However, in ethanol, the two shortest lifetimes ( 0.80 and 9.8 ps for $3 \mathbf{a}$ and 0.71 and 7.5 ps for $3 \mathbf{b}$ ) are in good agreement with the values found for solvent relaxation in this solvent ( 0.29 and 16 ps). ${ }^{73}$ At this point, we would like to emphasize that the occurrence of fast vibrational relaxation in these decays was discarded because similar fast transient times were obtained for $\mathbf{3 a}$ in acetonitrile, when excitation was performed with different pump energies (excitation at 455 and $420 \mathrm{~nm}$ ); see Table 4.

The longest decay components found in the fs-TA data are, within experimental error, in good agreement with the long decay time values obtained by TCSPC and are attributed to the excited singlet-state decay (Table 4), thus showing that radiative relaxation is a competitive channel for the excitedstate deactivation of $\mathbf{3 a}$ and $\mathbf{3 b}$.

It is worth noting the influence of the solvent properties on the long-lived components observed in both time-resolved fluorescence and transient absorption. A significant decrease in the longer decay components is observed on going from the aprotic solvent acetonitrile (2032 ps for $3 \mathbf{a}$ and 600 ps for $3 \mathbf{b}$ ) to the protic ethanol (1056 and 316 ps for $3 \mathbf{a}$ and $3 \mathbf{b}$, respectively); see Table 4. A similar decrease was previously reported for a $\mathrm{D}-\pi-\mathrm{A}$ molecule containing a carboxylicsubstituted rhodanine acceptor group and was attributed to the occurrence of ESPT through the interaction of the compound with protic solvents. ${ }^{74}$ From the concentration-dependent lifetimes, it was also shown that ESPT in aprotic and nonpolar solvents can occur through intermolecular interaction between the molecule's own carboxylic group and another molecule, associated by dimerization through hydrogen bonding. ${ }^{74}$ However, in our case, the latter effect can be excluded based on the low concentration used in the fluorescence lifetime measurements. In the case of the fs-TA data, although higher 


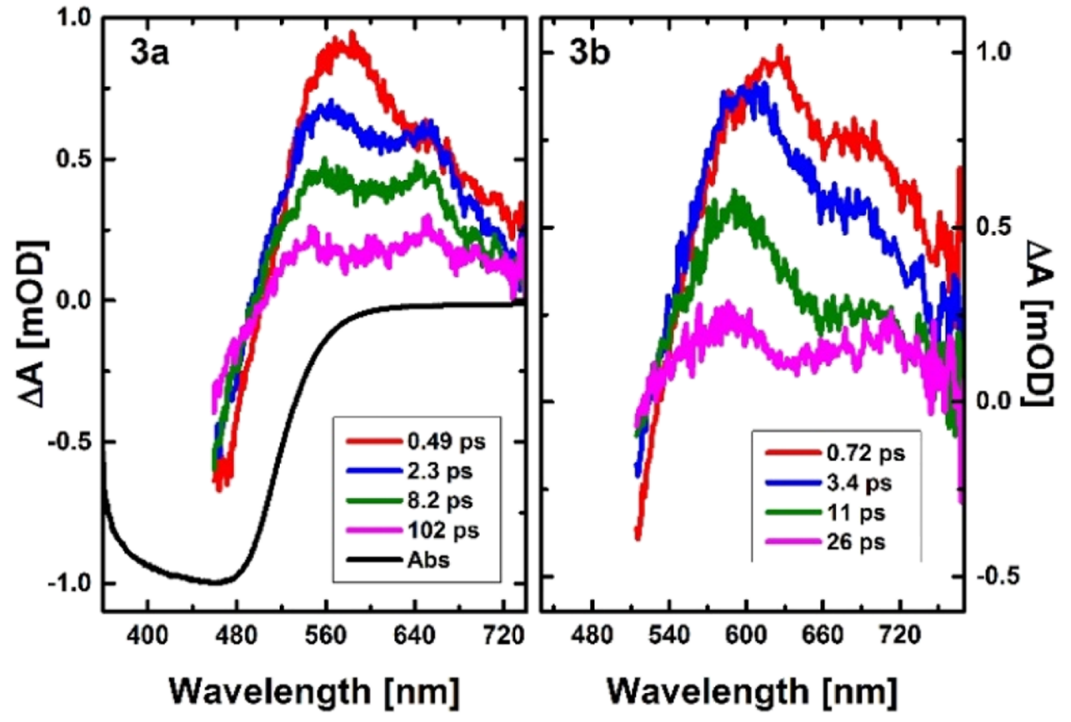

Figure 3. Time-resolved transient absorption data for the films of $\mathbf{3} \mathbf{a}$ and $\mathbf{3} \mathbf{b}$ adsorbed in $\mathrm{TiO}_{2}$ (wetted with acetonitrile) collected with excitation at 440 and $470 \mathrm{~nm}$, respectively. The normalized and inverted ground-state absorption spectrum for $3 \mathrm{a}$ adsorbed in the $\mathrm{TiO}_{2}$ film is also shown for comparison.

concentrations were used in these experiments (absorption $\leq 0.3$ in $2 \mathrm{~mm}$ optical path cuvettes), the good agreement between the long decay components in the fluorescence and transient absorption data (Table 4) leads us to exclude the occurrence of self-quenching through dimerization in these samples.

The nature of the transient lifetime with values in the $40-$ 119 ps range for $\mathbf{3 a}$ and 28 ps for $\mathbf{3 b}$ (Table 4) is not entirely clear. Although ESPT and isomerization (e.g., in the cyanoacetic group) can occur, these processes were previously ascribed to the longest decay component. ${ }^{72}$ Corroborating this is the observed decrease in the long decay component of $\mathbf{3 b}$ on going from acetonitrile to ethanol solution, whereas the 28 ps decay time remains unchanged. Furthermore, for the compounds investigated, photoisomerization is unlikely because it is expected that for such large molecules, isomerization should be very slow because the excess energy is distributed over many vibrational modes, so that it will take considerable time until enough energy ends up in the "critical mode," which drives the isomerization. ${ }^{32}$ Further support can be found in Figures S4 and S5 in the Supporting Information, where it can be seen that for $\mathbf{3 a}$ and $\mathbf{3 b}$, all kinetic traces completely decayed within the fs-TA time window (ca. $7.6 \mathrm{~ns}$ ), thus showing that the original ground-state population has been recovered.

Therefore, in agreement with the previous reports for $\mathrm{D}-\pi-$ A molecules containing cyano-acrylic and rhodanine groups, the transients with lifetimes in the range of $28-119$ ps are attributed to structural relaxation in the excited state. ${ }^{72,75,76}$ Thus the excited-state dynamics of the investigated compounds in acetonitrile and ethanol solution can be described through a series of sequential relaxation steps: (i) upon photoexcitation, the molecules in the ground state are vertically excited to a Franck-Condon state; (ii) this undergoes fast solvent relaxation (solvation dynamics) to a locally excited state; (iii) subsequent decay of the excited state through structural relaxation yields the relaxed excited state, from which the molecules deactivate to the ground state. ${ }^{72,75-78}$

2.5.2. fs-TA Study for $3 a$ and $3 b$ Adsorbed in $\mathrm{TiO}_{2}$ Films. Figure 3 depicts the time-resolved transient absorption spectra for the samples adsorbed on $\mathrm{TiO}_{2}$ films. These experiments were carried out with the films immersed in acetonitrile to replicate the presence of the electrolyte solution, as in the photovoltaic experiments (see the Experimental Section). In general, for $\mathbf{3 a}$ and $\mathbf{3 b}$, the fs-TA spectra present a positive transient absorption band in the $520-770 \mathrm{~nm}$ range together with a negative signal that represents the onset of the groundstate bleaching band (see the comparison with the ground-state absorption spectra in Figure 3). From the global analysis using a parallel model, three lifetime components were needed to properly fit the kinetic traces (Figure S6 and Table 4). From Figure 3, it can be seen that for both derivatives, the whole transient absorption spectrum uniformly decays with the transient decay lifetimes depicted in Table 4. In the $\mathrm{TiO}_{2}$ films, it is expected that the electron injection from the dye excited state (initially formed electron-cation complexes) to the $\mathrm{TiO}_{2} \mathrm{CB}$ occurs within the instrumental response function of our fs-TA system ( $<250 \mathrm{fs}$ ). This will formally produce the dye radical cation localized largely on the triphenylamine moiety. The absorption of the triphenylamine cation radical depends on the substituent and environment, but is generally in the $630-650 \mathrm{~nm}$ region. ${ }^{79,80}$ However, this is a simplification, and the physical assignment of the observed transient absorption dynamics on the $\mathrm{TiO}_{2}$ semiconductor surface is not trivial. Although similar time constants to the two shortest transient times of $3 \mathbf{a}$ ( 1.8 and 25 ps) and $3 \mathbf{b}$ ( 0.32 and 12 ps) were reported for $\mathrm{TiO}_{2}$ films of cyano-acrylic acid-substituted triphenylamines ( 0.8 and $12 \mathrm{ps)}$ and assigned to changes in a transient Stark field at the dye- $\mathrm{TiO}_{2}$ interface, the occurrence of this effect is not clear in our fs-TA data. ${ }^{75,76}$ Indeed, transient Stark effects (induced by changes in the local electric field of the photoexcited species, radical cations, and electrons) were observed by ultrafast pump-probe spectroscopy in a variety of systems including organic semiconductors, inorganic nanoparticles, and DSSCs. ${ }^{81}$ However, in our case, we could not identify the spectroscopic feature that corroborates the occurrence of such a Stark effect, that is, the characteristic blue shift of the ground-state absorption band when compared to the ground-state bleaching band obtained from the fs-TA spectra (see Figure 3). Because there is no clear evidence for 
Table 5. TD-DFT/CAM-B3LYP Calculated Vertical Excitation Energies ${ }^{a}\left(E_{\mathrm{ex}}\right)$, Wavelengths of Electronic Transitions $(\lambda)$, Main Contributions ${ }^{b}$ to the Excited States, Oscillator Strengths $(f)$, and Absorption Maxima $\left(\lambda_{\max }\right)$ Compared with Experimental UV-Visible Absorption Maxima for Dyes 3a and 3b

\begin{tabular}{|c|c|c|c|c|c|c|}
\hline $\begin{array}{l}\text { excited } \\
\text { state }\end{array}$ & $\begin{array}{l}E_{\mathrm{ex}}^{a} \\
{[\mathrm{eV}]}\end{array}$ & $\lambda[\mathrm{nm}]$ & main contributions ${ }^{b}[\%]$ & $f^{a}$ & $\begin{array}{l}\lambda_{\max } \\
{[\mathrm{nm}]}\end{array}$ & $\begin{array}{cl}\lambda_{\max } & (\mathrm{UV}-\mathrm{Vis}) \\
& {[\mathrm{nm}]}\end{array}$ \\
\hline \multicolumn{7}{|c|}{$3 a$} \\
\hline S1 & 2.85 & 435 & $\mathrm{H} \rightarrow \mathrm{L}(71 \%), \mathrm{H}-1 \rightarrow \mathrm{L}(23 \%), \mathrm{H} \rightarrow \mathrm{L}+1(4 \%)$ & 1.818 & 435 & 422 \\
\hline $\mathrm{S} 2$ & 3.81 & 325 & $\mathrm{H}-1 \rightarrow \mathrm{L}(58 \%), \mathrm{H} \rightarrow \mathrm{L}+1(22 \%), \mathrm{H} \rightarrow \mathrm{L}(11 \%), \mathrm{H}-5 \rightarrow \mathrm{L}(5 \%)$ & 0.062 & & \\
\hline S3 & 3.89 & 319 & $\mathrm{H}-2 \rightarrow \mathrm{L}(96 \%)$ & 0.070 & & \\
\hline \multicolumn{7}{|c|}{$3 b$} \\
\hline S1 & 2.75 & 451 & $\mathrm{H} \rightarrow \mathrm{L}(63 \%), \mathrm{H}-1 \rightarrow \mathrm{L}(30 \%), \mathrm{H} \rightarrow \mathrm{L}+1(4 \%)$ & 2.041 & 451 & 476 \\
\hline S3 & 3.63 & 342 & $\mathrm{H}-1 \rightarrow \mathrm{L}(47 \%), \mathrm{H} \rightarrow \mathrm{L}+1(20 \%), \mathrm{H} \rightarrow \mathrm{L}(13 \%), \mathrm{H}-4 \rightarrow \mathrm{L}(9 \%), \mathrm{H} \rightarrow \mathrm{L}+2(6 \%)$ & 0.158 & & \\
\hline S4 & 4.02 & 308 & $\mathrm{H}-2 \rightarrow \mathrm{L}(90 \%), \mathrm{H}-2 \rightarrow \mathrm{L}+1(4 \%)$ & 0.077 & & \\
\hline
\end{tabular}

${ }^{a}$ Results are shown for excitation energies lower than $4.1 \mathrm{eV}$ and $f$ larger than $0.05 .{ }^{b}$ Only the contributions $\geq 2 \%$ are indicated.

any transient Stark shift, the three time constants necessary to fit the fs-TA decay dynamics of the investigated dyes are better assigned to recombination between the cations and trapped electrons. In support of this, the recombination lifetime strongly depends on the distance of electrons and cations in the complexes, and thus multiexponential decay kinetics is expected for this process. ${ }^{75,76}$

Comparison between the recombination lifetimes of $\mathbf{3 a}$ and $\mathbf{3 b}$ shows that these values are longer for the former than for $\mathbf{3 b}$ ( 1.8 vs 0.32 ps, 25 vs 12 ps, and 2174 vs 120 ps, respectively). This provides at least a partial explanation for the 10 times higher photovoltaic efficiency found for $3 \mathbf{a}$ compared with $\mathbf{3 b}$ (see Table 2). Longer recombination lifetimes should, in principle, give more time for the electron-cation complex to dissociate (charge separation) and for electron migration to occur, thus enhancing the photovoltaic efficiency. In addition, theoretical work previously reported for rhodanine-3-acetic acid $\mathrm{D}-\pi-\mathrm{A}$ systems showed that the delocalization of the excited state is broken between the 4-oxo-2-thioxothiazolidine ring and the $-\mathrm{COOH}$ anchoring group because of the $\mathrm{CH}_{2}$ group, which affects the electron injection from molecules with rhodanine-like acceptors to the $\mathrm{CB}$ of $\mathrm{TiO}_{2} \cdot{ }^{66}$ DFT calculations on dyes $\mathbf{3 a}$ and $\mathbf{3 b}$ are presented in the next section. However, the effect on the injection is not totally clear in our timeresolved data, as adsorption on $\mathrm{TiO}_{2}$ leads to a decrease of the excited-state associated lifetimes in both molecules, and from the present fs-TA data, the principal process hampering the photovoltaic performance of $\mathbf{3} \mathbf{b}$ should be the fast recombination times.

2.6. Theoretical Calculations. To obtain further insight into the distinct differences in the structures, electronic properties, and photovoltaic performance of dyes $3 \mathbf{a}-\mathbf{b}$, a combined DFT and time-dependent DFT (TD-DFT) computational study was performed. Dyes $\mathbf{3 a}$ and $\mathbf{3 b}$ can have several different isomers, depending on the relative arrangement of some of their units. These can have different degrees of conjugation and possibly very different electronic structures. A total of twelve isomers of dye $3 \mathbf{a}$ and four isomers of dye $\mathbf{3 b}$ were studied, resulting from the consideration of both $E$ and $Z$ configurations and the different conformational arrangements between the carboxylic acid moiety, the cyano group, and the adjacent thienothiophene spacer in dye 3a and between the rhodanine ring and the neighboring thienothiophene moiety in dye $3 \mathrm{~b}$. The structures and energies were determined for these isomers at the DFT/Becke three parameter Lee-Yang-Parr (B3LYP) level of theory, taking into account the bulk solvent effects of chloroform; the optimized geometries of the most stable form of each dye are shown in Figure S7 in the Supporting Information.

These forms account for approximately 64 and $92 \%$ of the population for dyes $\mathbf{3 a}$ and $\mathbf{3 b}$, respectively (the structures of all isomers studied together with the relative energies and approximate populations are given in the Supporting Information, see Figures S8 and S9 and Table S2). The DFT calculations indicate that dye $\mathbf{3 b}$ is slightly less planar than $\mathbf{3 a}$ in the region between the donor and the $\pi$-bridge, with a torsion angle between the phenyl group of triphenylamine and the thienothiophene group of $21.3^{\circ}$, compared to $18.8^{\circ}$ in dye $3 a$. Additionally, while the region between the thienothiophene spacer and the acceptor is essentially planar in $3 \mathbf{a}$, favoring the efficient electron transfer into $\mathrm{TiO}_{2}$, in $3 \mathbf{b}$, the $-\mathrm{COOH}$ acceptor/anchoring group is almost at a $90^{\circ}$ plane relative to the rhodanine ring. This hampers the electron injection from $3 \mathrm{~b}$ into the semiconductor.

Table S3 in the Supporting Information shows the calculated relative free energy, approximate population, and energies of the frontier molecular orbitals for the three major isomers of $\mathbf{3 a}$ and the two major isomers of $\mathbf{3 b}$. The energies of the HOMO and LUMO orbitals calculated for dyes 3a [isomer (E)-3a-I, -5.05 and $-2.64 \mathrm{eV}$, respectively] and $3 \mathbf{b}$ [isomer $(Z)-3 \mathbf{b}-\mathrm{I}$, -5.00 and $-2.71 \mathrm{eV}$, respectively] match very well with the experimental $\mathrm{CV}$ values $(-5.07$ and $-2.69 \mathrm{eV}$ for $3 \mathrm{a}$ and -5.03 and $-2.88 \mathrm{eV}$ for $3 \mathbf{b}$, respectively).

The 14 lowest singlet-singlet vertical electronic transitions have been calculated by TD-DFT/CAM-B3LYP for the most stable conformers of 3a, (E)-3a-I, and of $3 \mathbf{b},(Z)-3 \mathbf{b}-\mathbf{I}$. This long-range corrected density functional has been found to perform well in the calculation of excited states with a significant charge-transfer character, such as the case of the dyes in our study. ${ }^{79,80}$

Table S3 in the Supporting Information gives the absorption maxima for the three major isomers of dye $3 \mathbf{a}$ and the two major isomers of dye $\mathbf{3 b}$, and Table 5 shows the assignments of the electronic transitions for the dominant isomers (E)-3a-I and $(Z)-3 b-I$. The TD-DFT results shown in Table 5 indicate that the absorption spectrum of $3 \mathbf{a}$ has a strong band at a calculated wavelength of $435 \mathrm{~nm}$ (experimental wavelength at $422 \mathrm{~nm}$ ), which corresponds essentially to a HOMO $\rightarrow$ LUMO transition (71\%) with a significant contribution from a HOMO - $1 \rightarrow$ LUMO transition (23\%) and a very small (4\%) contribution from a HOMO $\rightarrow$ LUMO + 1 configuration. The remaining bands in the region above $300 \mathrm{~nm}$ (calculated wavelengths at 325 and $319 \mathrm{~nm}$ ) involve transitions between $\mathrm{HOMO}-5$, HOMO - 2, HOMO - 1, and HOMO to 


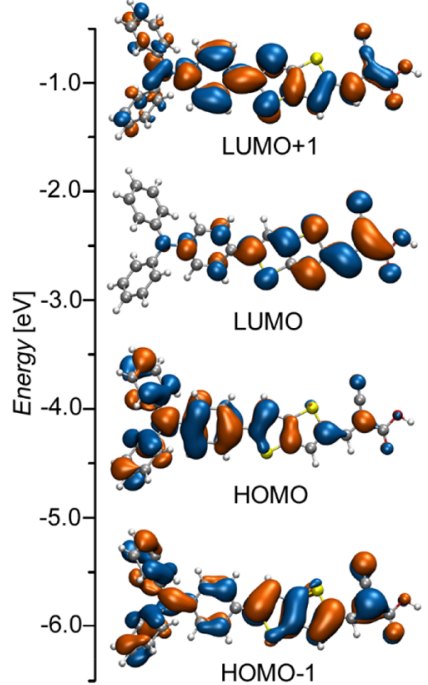

a)

\section{$-1.05 \mathrm{eV}$}

$-1.41 \mathrm{eV}$

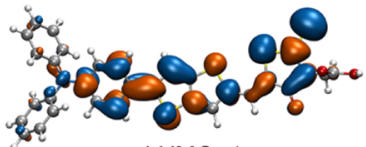

LUMO+1

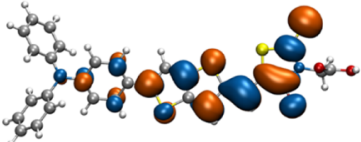

LUMO

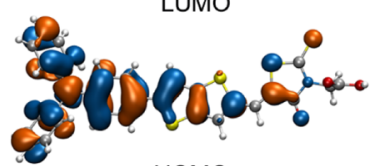

HOMO

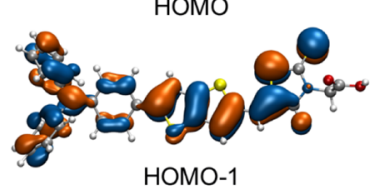

b)

Figure 4. Orbital density distribution and energies (DFT/B3LYP) of the frontier molecular orbitals of dyes (a) 3a (3a-I) and (b) 3b (3b-I). The black solid lines indicate the calculated energies of the orbitals, and the green solid lines indicate the experimental $\mathrm{CV}$ values. The arrows indicate the TD-DFT/CAM-B3LYP main contributions to the $S_{1}$ excited states for each dye. The blue dashed line indicates the level of the CB edge of the anatase $\mathrm{TiO}_{2}$ surface $(-4.0 \mathrm{eV}$ vs vacuum $)$ and the gray dashed line indicates the $\mathrm{I}^{-} / \mathrm{I}_{3}{ }^{-}$redox potential $(-4.6 \mathrm{eV}$ vs vacuum $)$.

LUMO and LUMO + 1 and have very low oscillator strengths. The absorption spectrum of $\mathbf{3 b}$ has a strong band at a calculated wavelength of $451 \mathrm{~nm}$ (experimental value at 476 $\mathrm{nm}$ ), which corresponds to the same electronic transitions as in 3a, however, with slightly different contributions (63\% from HOMO $\rightarrow$ LUMO, 30\% from HOMO - $1 \rightarrow$ LUMO, and $4 \%$ from HOMO $\rightarrow$ LUMO +1 ). The remaining bands in the region above $300 \mathrm{~nm}$ in the absorption spectrum of $3 \mathrm{~b}$ (calculated wavelengths at 345 and $331 \mathrm{~nm}$ ) also have low oscillator strengths.

Therefore, the dominant bands in the absorption spectra of $\mathbf{3 a}$ and $\mathbf{3 b}$ correspond essentially to HOMO $\rightarrow$ LUMO transitions. In Figure 4, we analyze the type of orbitals involved in these transitions and present the energy diagram of the frontier molecular orbitals of dyes $3 \mathbf{a}$ and $\mathbf{3 b}$ calculated at the DFT/B3LYP level. The HOMOs of $\mathbf{3 a}$ and $\mathbf{3 b}$ are $\pi$ orbitals localized essentially on the triphenylamine donor and on the adjacent thienothiophene spacer. The electron density of the LUMO of $\mathbf{3 a}$ is mainly localized on the thienothiophene bridge and the anchoring group $(-\mathrm{COOH})$. Therefore, when this dye is linked to $\mathrm{TiO}_{2}$, the LUMO centered on the anchoring moiety should enhance the orbital overlap with the titanium $3 \mathrm{~d}$ orbitals and subsequently favor the electron injection to the $\mathrm{CB}$ of $\mathrm{TiO}_{2}$.

By contrast, the LUMO of $\mathbf{3 b}$ is mainly centered on the thienothiophene spacer and on the 4-oxo-2-thioxothiazolidine ring, particularly on the carbonyl and thiocarbonyl groups, such that the maximum electron density of the LUMO is isolated from the $-\mathrm{COOH}$ anchoring group because of the presence of the $-\mathrm{CH}_{2}-$ linker group. This, therefore, prevents the $3 \mathbf{b}$ electrons from being efficiently injected into the $\mathrm{CB}$ of $\mathrm{TiO}_{2}$ via the carboxyl group. ${ }^{57,61,64-68}$

Thus, the HOMO-LUMO excitation in these dyes has the nature of charge transfer from the triphenylamine donor to the anchoring cyanoacetic group in $\mathbf{3 a}$ and rhodanine-3-acetic acid in $3 \mathbf{b}$. This charge separation is convenient for DSSCs because it facilitates the electron injection from the excited dye into the $\mathrm{TiO}_{2}$ electrode and also slows down the recombination of the injected electrons with the oxidized dye molecules. The structure of the anchoring group in $\mathbf{3 b}$, however, introduces some loss of efficiency because the LUMO of $\mathbf{3 b}$ is not localized on the anchoring group $\left(-\mathrm{CH}_{2} \mathrm{COOH}\right)$ of the 4-oxo2-thioxothiazolidine ring because of the methylene group, which reduces (Figure $4 \mathrm{~b}$ ) the probability of injection of the excited electrons into the $\mathrm{TiO}_{2} \mathrm{CB}$. $^{57,61,64-68}$

Comparing the energy levels of the HOMO - 1, HOMO, LUMO, and LUMO + 1 orbitals of the dyes, we can see that the substitution of the cyanoacetic group by rhodanine-3-acetic acid leads to the stabilization of the LUMO and LUMO + 1 and a destabilization of the HOMO -1 and HOMO of $3 \mathbf{b}$, with the consequent narrowing of the gaps between the orbitals. This explains the red shift in the absorption maximum in $\mathbf{3 b}$.

The energy diagram in Figure 4 also shows the position of the HOMO and LUMO energy levels of the dyes compared with the $\mathrm{TiO}_{2} \mathrm{CB}$ edge level $(-4.0 \mathrm{eV} \text { vs vacuum })^{82}$ and the redox potential of the redox couple $3 \mathrm{I}^{-} / \mathrm{I}_{3}^{-}(-4.6 \mathrm{eV}$ vs vacuum $).{ }^{83}$ For both dyes, the LUMO level is higher than that of the $\mathrm{TiO}_{2} \mathrm{CB}$ edge, providing the thermodynamic driving force for the efficient electron injection into the $\mathrm{CB}$ of the semiconductor. Further, the HOMO levels in both dyes are lower than the iodide redox potential, allowing fast dye regeneration. These results are consistent with the $\mathrm{CV}$ measurements.

\section{CONCLUSIONS}

We have studied the effect of the acceptor/anchoring group on two thieno $[3,2-b]$ thiophene dyes $3 \mathbf{a}-\mathbf{b}$ as sensitizers in nanocrystalline $\mathrm{TiO}_{2}$ DSSCs. The dyes were obtained in moderate-to-excellent yields by the Suzuki-Miyaura coupling reaction, followed by Knoevenagel condensation. Compound 3a, bearing cyanoacetic acid as the acceptor/anchoring group, exhibits a better conversion efficiency in DSSCs than $\mathbf{3 b}$, which has rhodanine-3-acetic acid as the electron withdrawing and anchoring unit. This was attributed to the effective and faster electron injection from the LUMO of 3a dye to the CB of $\mathrm{TiO}_{2}$ 
and reduction of the dye recombination. Theoretical and experimental studies suggest that rhodanine-3-acetic acid is not a good anchoring group because of the broken conjugation between the acceptor and anchor from the intervening methylene group. This confirms the importance of a donor, acceptor and anchor in the dye properties.

Enhanced power conversion efficiencies were observed by coadsorption of dye 3a with N719. The best photovoltaic performance obtained for the DSSC prepared with the $25 / 75$ volume percent ratio of $3 \mathrm{a} / \mathrm{N} 719$ displayed $6.05 \%$ energy conversion efficiency.

\section{EXPERIMENTAL SECTION}

4-(Diphenylamino)phenylboronic acid pinacol ester and cyanoacetic acid were purchased from Aldrich. Rhodanine-3-acetic acid was purchased from Alfa Aesar. All commercially available reagents and solvents were used as received. The 5bromothieno[3,2-b] thiophene-2-carbaldehyde precursor was prepared using the same synthetic methodology previously reported by us. ${ }^{58}$ The reaction progress was monitored by thinlayer chromatography, using $0.25 \mathrm{~mm}$ thick precoated silica plates (Merck Fertigplatten Kieselgel 60 F254), and the spots were visualized under ultraviolet light. Purification was achieved by silica gel column chromatography (Merck Kieselgel, 230400 mesh).

Nuclear magnetic resonance (NMR) spectra were obtained on a Bruker AVANCE II 400 spectrometer at an operating frequency of $400 \mathrm{MHz}$ for ${ }^{1} \mathrm{H}$ (see Figures $\mathrm{S} 10-\mathrm{S} 12$ in the Supporting Information) and $100.6 \mathrm{MHz}$ for ${ }^{13} \mathrm{C}$, using the solvent peak as the internal reference (see the Supporting Information for further details).

Melting points were determined on a Gallenkamp apparatus and are uncorrected. Infrared spectra were recorded on a BOMEM MB 104 spectrophotometer. Absorption and fluorescence emission spectra were collected with a Shimadzu UV/2501PC and a Horiba-Jobin-Yvon FluoroMax-4 spectrophotometer, respectively. Fluorescence quantum yields were determined using rhodamine 6G $\left(\phi_{\mathrm{F}}=0.95\right)$ in ethanol solution. ${ }^{84}$ Mass spectrometry analysis was performed at the C.A.C.T.I.-Unidad de Espectrometria de Masas of the University of Vigo, Spain.

The synthetic procedures for precursor aldehyde $\mathbf{2}$ and the investigated triphenylamine-thienothiophenes $3 \mathbf{a}-\mathbf{b}$ are described in the Supporting Information.

$\mathrm{CV}$ was performed using an AUTOLAB electrochemical station in a three-electrode cell configuration, as elsewhere reported, ${ }^{59}$ and measured at a scan rate of $0.1 \mathrm{~V} \mathrm{~s}^{-1}$ (see Figure S13). The solutions were deoxygenated by bubbling nitrogen before each measurement. The concentration of dyes was 1 $\mathrm{mM}$ with $0.1 \mathrm{M}\left[\mathrm{NBu}_{4}\right]\left[\mathrm{BF}_{4}\right]$ as the supporting electrolyte in the dry DMF solvent. The electrode potentials were reported in relation to that of the $\mathrm{Fc}^{+} / \mathrm{Fc}$ redox couple. ${ }^{59,60}$

Molecular structure calculations for compounds $\mathbf{3} \mathbf{a}-\mathbf{b}$ were performed on the DFT level with the B3LYP exchange correlation functional, which combines the hybrid exchange functional of Becke ${ }^{85}$ with the correlation functional of Lee, Yang, and Parr. ${ }^{86}$ No symmetry constraints were imposed, and the all-electron $6-31 \mathrm{G}(\mathrm{d}, \mathrm{p})$ double- $\zeta$ plus polarization basis sets were used for all atoms. The effects of the bulk solvent (chloroform) were considered using the polarizable continuum model (PCM). ${ }^{87}$ In this model, the solute molecules are placed into a spherical cavity surrounded by a dielectric continuum. Default van der Waals radii were used in PCM for all atoms.
Additionally, the molecular structures of the most stable isomers of compounds $\mathbf{3} \mathbf{a}-\mathbf{b}$ were optimized with the CAM$B 3 L Y P^{88}$ functional. At the final equilibrium geometries with minimum energy, the maximum gradient was $1 \times 10^{-6}$ or $1 \times$ $10^{-5}$ hartree $\mathrm{bohr}^{-1}$. The vibrational frequencies were calculated for all equilibrium structures to confirm that they are true minima (i.e., no imaginary frequencies). The vertical excitation energies were calculated by TD-DFT for the 14 lowest singlet-excited states, using the CAM-B3LYP ${ }^{88}$ functional with the $6-311 \mathrm{G}(\mathrm{d}, \mathrm{p})$ triple- $\zeta$ plus polarization basis sets to analyze the absorption properties of the dyes. The bulk solvent effects of chloroform were also taken into account in the TD-DFT calculations. All calculations were carried out using the GAMESS-US code. ${ }^{89}$

The ultrafast transient spectroscopic and kinetic measurements were performed in a Helios spectrometer (Ultrafast Systems) with an instrumental response function of around 250 fs (apparatus described elsewhere); ${ }^{90}$ see the Supporting Information for further details. The spectral chirp of the data was corrected using Surface Xplorer PRO program from Ultrafast Systems. Global analysis of the data (using a sequential model) was performed using Glotaran software. ${ }^{91}$

Porous $\mathrm{TiO}_{2}$ films (about $1 \mu \mathrm{m}$ thick) for the fast dynamics studies were made by spreading $\mathrm{TiO}_{2}$ paste (Ti-Nanoxide $\mathrm{T} /$ SP, from Solaronix SA) onto a glass microscope slide, using Scotch Magic tape as a spacer. The film paste was then sintered up to $500{ }^{\circ} \mathrm{C}$. When the films had cooled to about $80{ }^{\circ} \mathrm{C}$, they were placed in a dye solution $(0.2 \mathrm{mM}$, ethanol) for adsorption of the sensitizer for $1 \mathrm{~min}$. For kinetic experiments, a drop of acetonitrile was poured into the sensitized films, which were then covered with a second microscope slide.

Fluorescence decays were measured using a home-built TCSPC apparatus, as elsewhere described. ${ }^{92}$ The fluorescence decays were analyzed using the method of modulating functions implemented by Striker. ${ }^{93}$

DSSCs were prepared, as described in the Supporting Information. The photovoltaic performance was obtained with an Oriel Class solar simulator and a ZENNIUM workstation, using a metal mask with an aperture area of $0.2 \mathrm{~cm}^{2}$, as previously reported. ${ }^{59}$

\section{ASSOCIATED CONTENT}

\section{Supporting Information}

The Supporting Information is available free of charge on the ACS Publications website at DOI: 10.1021/acsomega.7b01195.

Absorption and emission data and spectra; fluorescence data; photophysical data; fluorescence lifetimes; decayassociated spectra and kinetics traces from ultrafast transient absorption; calculated optimized geometries and free energies for the $\mathbf{3} \mathbf{a}$ and $\mathbf{3 b}$ isomers; experimental procedures; infrared data; NMR data and spectra; melting points; mass spectrometry; cyclic voltammetry data and voltammograms (PDF)

\section{AUTHOR INFORMATION}

\section{Corresponding Authors}

*E-mail: jpina@qui.uc.pt (J.P.).

*E-mail: mfox@quimica.uminho.pt (M.M.M.R.).

ORCID

Carlos Serpa: 0000-0001-7004-0110

Licínia L. G. Justino: 0000-0002-8338-6441

M. Manuela M. Raposo: 0000-0002-7996-1626 


\section{Present Address}

"Universidade do Minho Instituto de Polímeros e Compósitos, Departamento de Engenharia de Polímeros Campus de Azurém, 4800-058 Guimarães, M. Cidália R. Castro (M.C.R.C.).

\section{Notes}

The authors declare no competing financial interest.

\section{ACKNOWLEDGMENTS}

The authors thank Fundação para a Ciência e Tecnologia (FCT) for PhD grants to S.S.M.F. (SFRH/BD/87786/2012) and M.C.R.C. (SFRH/BD/78037/2011) and postdoctoral grants to L.L.G.J. (SFRH/BPD/97026/2013) and J.P. (SFRH/BPD/108469/2015). The authors also thank FEDER-COMPETE for the financial support through the CQ/UM PEst-C/QUI/UI0686/2013 (FCOMP-01-0124FEDER-037302). The NMR spectrometer Bruker AVANCE III 400 is part of the National NMR Network and was purchased within the framework of the National Program for Scientific Re-equipment, contract REDE/1517/RMN/2005 with funds from POCI 2010 (FEDER) and FCT. The group in Coimbra are grateful for funding from "Centro de Quimica de Coimbra," which is supported by the Fundação para a Ciência e a Tecnologia (FCT), Portuguese Agency for Scientific Research, through the programs UID/QUI/ UI0313/2013 and COMPETE. The authors also thank the Laboratory for Advanced Computing at the University of Coimbra for providing computing resources that have contributed to the research results reported in this paper (URL http://www.lca.uc.pt). This work was performed under the project "SunStorage-harvesting and storage of solar energy," with reference POCI-01-0145-FEDER-016387, funded by the European Regional Development Fund (ERDF), through COMPETE 2020-Operational Programme for Competitiveness and Internationalization (OPCI), and by national funds through FCT. The research leading to these results has received funding from Laserlab-Europe (grant agreement no. 284464, EC's Seventh Framework Programme). A.I.P. would like to acknowledge the European Commission through the Seventh Framework Programme, the Specific Programme "Ideas" of the European Research Council for research and technological development as part of an Advanced Grant under grant agreement no. 321315, which also partially funded this work. The authors would also like to acknowledge L. Andrade and I. Mesquita for their valuable contribution for the article.

\section{REFERENCES}

(1) O’Regan, B.; Grätzel, M. A low-cost, high-efficiency solar cell based on dye-sensitized colloidal $\mathrm{TiO}_{2}$ films. Nature 1991, 353, 737740.

(2) Yella, A.; Lee, H.-W.; Tsao, H. N.; Yi, C.; Chandiran, A. K.; Nazeeruddin, M. K.; Diau, E. W.-G.; Yeh, C.-Y.; Zakeeruddin, S. M.; Grätzel, M. Porphyrin-sensitized solar cells with cobalt (II/III)-based redox electrolyte exceed 12 percent efficiency. Science 2011, 334, 629634.

(3) Grätzel, M. Dye-sensitized solar cells. J. Photochem. Photobiol., C 2003, 4, 145-153.

(4) Grätzel, M. Conversion of sunlight to electric power by nanocrystalline dye-sensitized solar cells. J. Photochem. Photobiol., A 2004, 164, 3-14.

(5) Grätzel, M. Recent advances in sensitized mesoscopic solar cells. Acc. Chem. Res. 2009, 42, 1788-1798.
(6) Bignozzi, C. A.; Argazzi, R.; Boaretto, R.; Busatto, E.; Carli, S.; Ronconi, F.; Caramori, S. The role of transition metal complexes in dye sensitized solar devices. Coord. Chem. Rev. 2013, 257, 1472-1492.

(7) Pashaei, B.; Shahroosvand, H.; Graetzel, M.; Nazeeruddin, M. K. Influence of ancillary ligands in dye-sensitized solar cells. Chem. Rev. 2016, 116, 9485-9564.

(8) Higashino, T.; Nimura, S.; Sugiura, K.; Kurumisawa, Y.; Tsuji, Y.; Imahori, H. Photovoltaic properties and long-term durability of porphyrin-sensitized solar cells with silicon-based anchoring groups. ACS Omega 2017, 2, 6958-6967.

(9) Kwon, D. Y.; Chang, D. M.; Kim, Y. S. Effect of electron withdrawing unit for dye-sensitized solar cell based on D-A- $\pi$-A organic dyes. Mater. Res. Bull. 2014, 58, 93-96.

(10) Ren, X.; Jiang, S.; Cha, M.; Zhou, G.; Wang, Z.-S. Thiophenebridged double D- $\pi$-A dye for efficient dye-sensitized solar cell. Chem. Mater. 2012, 24, 3493-3499.

(11) Robertson, N. Optimizing dyes for dye-sensitized solar cells. Angew. Chem., Int. Ed. 2006, 45, 2338-2345.

(12) Ooyama, Y.; Harima, Y. Molecular designs and syntheses of organic dyes for dye-sensitized solar cells. Eur. J. Org. Chem. 2009, 18, 2903-2934.

(13) Ning, Z.; Fu, Y.; Tian, H. Improvement of dye-sensitized solar cells: what we know and what we need to know. Energy Environ. Sci. 2010, 3, 1170-1181.

(14) Ooyama, Y.; Harima, Y. Photophysical and electrochemical properties, and molecular structures of organic dyes for dye-sensitized solar cells. ChemPhysChem 2012, 13, 4032-4080.

(15) Kanaparthi, R. K.; Kandhadi, J.; Giribabu, L. Metal-free organic dyes for dye-sensitized solar cells: recent advances. Tetrahedron 2012, 68, 8383-8393.

(16) Kim, B.-G.; Chung, K.; Kim, J. Molecular design principle of allorganic dyes for dye-sensitized solar cells. Chem.-Eur. J. 2013, 19, $5220-5230$

(17) Ahmad, S.; Guillén, E.; Kavan, L.; Grätzel, M.; Nazeeruddin, M. K. Metal free sensitizer and catalyst for dye sensitized solar cells. Energy Environ. Sci. 2013, 6, 3439-3466.

(18) Sugathan, V.; John, E.; Sudhakar, K. Recent improvements in dye sensitized solar cells: A review. Renewable Sustainable Energy Rev. 2015, 52, 54-64.

(19) Obotowo, I. N.; Obot, I. B.; Ekpe, U. J. Organic sensitizers for dye-sensitized solar cell (DSSC): Properties from computation, progress and future perspectives. J. Mol. Struct. 2016, 1122, 80-87.

(20) Chaurasia, S.; Lin, J. T. Metal-free sensitizers for dye-sensitized solar cells. Chem. Rec. 2016, 16, 1311-1336.

(21) Maçaira, J.; Andrade, L.; Mendes, A. Modeling, simulation and design of dye sensitized solar cells. RSC Adv. 2014, 4, 2830-2844.

(22) Gonçalves, L. M.; de Zea Bermudez, V.; Ribeiro, H. A.; Mendes, A. M. Dye-sensitized solar cells: A safe bet for the future. Energy Environ. Sci. 2008, 1, 655-667.

(23) Clifford, J. N.; Martínez-Ferrero, E.; Viterisi, A.; Palomares, E. Sensitizer molecular structure-device efficiency relationship in dye sensitized solar cells. Chem. Soc. Rev. 2011, 40, 1635-1646.

(24) Kim, J. Y.; Kim, Y. H.; Kim, Y. S. Indoline dyes with various acceptors for dye-sensitized solar cells. Curr. Appl. Phys. 2011, 11, S117-S121.

(25) Hagfeldt, A.; Boschloo, G.; Sun, L.; Kloo, L.; Pettersson, H. Dye-sensitized solar cells. Chem. Rev. 2010, 110, 6595-6663.

(26) Choi, H.; Baik, C.; Kang, S. O.; Ko, J.; Kang, M.-S.; Nazeeruddin, M. K.; Grätzel, M. Highly efficient and thermally stable organic sensitizers for solvent-free dye-sensitized solar cells. Angew. Chem. 2008, 120, 333-336.

(27) Zhang, G.; Bala, H.; Cheng, Y.; Shi, D.; Lv, X.; Yu, Q.; Wang, P. High efficiency and stable dye-sensitized solar cells with an organic chromophore featuring a binary $\pi$-conjugated spacer. Chem. Commun. 2009, 16, 2198-2200.

(28) Choi, H.; Raabe, I.; Kim, D.; Teocoli, F.; Kim, C.; Song, K.; Yum, J.-H.; Ko, J.; Nazeeruddin, M. K.; Grätzel, M. High molar extinction coefficient organic sensitizers for efficient dye-sensitized solar cells. Chem.-Eur. J. 2010, 16, 1193-1201. 
(29) Paek, S.; Choi, H.; Choi, H.; Lee, C.-W.; Kang, M.-s.; Song, K.; Nazeeruddin, M. K.; Ko, J. Molecular engineering of efficient organic sensitizers incorporating a binary $\pi$-conjugated linker unit for dyesensitized solar cells. J. Phys. Chem. C 2010, 114, 14646-14653.

(30) Tsao, H. N.; Burschka, J.; Yi, C.; Kessler, F.; Nazeeruddin, M. K.; Grätzel, M. Influence of the interfacial charge-transfer resistance at the counter electrode in dye-sensitized solar cells employing cobalt redox shuttles. Energy Environ. Sci. 2011, 4, 4921-4924.

(31) Metri, N.; Sallenave, X.; Plesse, C.; Beouch, L.; Aubert, P.-H.; Goubard, F.; Chevrot, C.; Sini, G. Processable star-shaped molecules with triphenylamine core as hole-transporting materials: experimental and theoretical approach. J. Phys. Chem. C 2012, 116, 3765-3772.

(32) Wu, Y.; Marszalek, M.; Zakeeruddin, S. M.; Zhang, Q.; Tian, H.; Grätzel, M.; Zhu, W. High-conversion-efficiency organic dye-sensitized solar cells: molecular engineering on $\mathrm{D}-\mathrm{A}-\pi$-A featured organic indoline dyes. Energy Environ. Sci. 2012, 5, 8261-8272.

(33) Cai, S.; Tian, G.; Li, X.; Su, J.; Tian, H. Efficient and stable DSSC sensitizers based on substituted dihydroindolo[2,3- $b]$ carbazole donors with high molar extinction coefficients. J. Mater. Chem. A 2013, $1,11295-11305$.

(34) Gao, P.; Tsao, H. N.; Yi, C.; Grätzel, M.; Nazeeruddin, M. K. Extended $\pi$-bridge in organic dye-sensitized solar cells: the longer, the better? Adv. Energy Mater. 2014, 4, 1301485.

(35) Kakiage, K.; Aoyama, Y.; Yano, T.; Otsuka, T.; Kyomen, T.; Unno, M.; Hanaya, M. An achievement of over 12 percent efficiency in an organic dye-sensitized solar cell. Chem. Commun. 2014, 50, 63796381.

(36) Lee, M.-W.; Kim, J.-Y.; Lee, D.-H.; Ko, M. J. Novel D- $\pi$-A organic dyes with thieno[3,2-b] thiophene-3,4-ethylenedioxythiophene unit as a $\pi$-bridge for highly efficient dye-sensitized solar cells with long-term stability. ACS Appl. Mater. Interfaces 2014, 6, 4102-4108.

(37) Kakiage, K.; Aoyama, Y.; Yano, T.; Oya, K.; Fujisawa, J.-i.; Hanaya, M. Highly-efficient dye-sensitized solar cells with collaborative sensitization by silyl-anchor and carboxy-anchor dyes. Chem. Commun. 2015, 51, 15894-15897.

(38) $\mathrm{Wu}, \mathrm{Y}$.; Zhu, W. Organic sensitizers from D- $\pi$-A to D-A- $\pi$-A: effect of the internal electron-withdrawing units on molecular absorption, energy levels and photovoltaic performances. Chem. Soc. Rev. 2013, 42, 2039-2058.

(39) Yen, Y.-S.; Chou, H.-H.; Chen, Y.-C.; Hsu, C.-Y.; Lin, J. T. Recent developments in molecule-based organic materials for dyesensitized solar cells. J. Mater. Chem. 2012, 22, 8734-8747.

(40) Marinado, T.; Hagberg, D. P.; Hedlund, M.; Edvinsson, T.; Johansson, E. M. J.; Boschloo, G.; Rensmo, H.; Brinck, T.; Sun, L.; Hagfeldt, A. Rhodanine dyes for dye-sensitized solar cells: spectroscopy, energy levels and photovoltaic performance. Phys. Chem. Chem. Phys. 2009, 11, 133-141.

(41) Mishra, A.; Fischer, M. K. R.; Bäuerle, P. Metal-free organic dyes for dye-sensitized solar cells: from structure: property relationships to design rules. Angew. Chem., Int. Ed. 2009, 48, 2474-2499.

(42) Koumura, N.; Wang, Z.-S.; Mori, S.; Miyashita, M.; Suzuki, E.; Hara, K. Alkyl-functionalized organic dyes for efficient molecular photovoltaics. J. Am. Chem. Soc. 2006, 128, 14256-14257.

(43) Wang, J.; Liu, K.; Ma, L.; Zhan, X. Triarylamine: versatile platform for organic, dye-sensitized, and perovskite solar cells. Chem. Rev. 2016, 116, 14675-14725.

(44) Cheng, Y.-J.; Yang, S.-H.; Hsu, C.-S. Synthesis of conjugated polymers for organic solar cell applications. Chem. Rev. 2009, 109, 5868-5923.

(45) Pellejà, L.; Dominguez, R.; Aljarilla, A.; Clifford, J. N.; de la Cruz, P.; Langa, F.; Palomares, E. Use of thienylenevinylene and ethynyl molecular bridges in organic dyes for dye-sensitized solar cells: implications for device performance. ChemElectroChem 2014, 1, $1126-1129$

(46) Xie, M.; Wang, J.; Bai, F.-Q.; Hao, L.; Zhang, H.-X. Discovering the intermediate of dye regeneration in dye-sensitized solar cells: Theoretical investigations on the interaction between organic dye with different donors and $\mathrm{X}-/ \mathrm{X} 3-(\mathrm{X}=\mathrm{I}, \mathrm{Br})$. Dyes Pigm. 2015, 120, 7484.
(47) Gupta, A.; Ali, A.; Gao, M.; Singh, T. B.; Bilic, A.; Watkins, S. E.; Bach, U.; Evans, R. A. Small molecules containing rigidified thiophenes and a cyanopyridone acceptor unit for solution-processable bulkheterojunction solar cells. Dyes Pigm. 2015, 119, 122-132.

(48) Ning, Z.; Tian, H. Triarylamine: a promising core unit for efficient photovoltaic materials. Chem. Commun. 2009, 37, 5483-5495.

(49) Mahmood, A. Triphenylamine based dyes for dye sensitized solar cells: A review. Sol. Energy 2016, 123, 127-144.

(50) Cinar, M. E.; Ozturk, T. Thienothiophenes, dithienothiophenes, and thienoacenes: syntheses, oligomers, polymers, and properties. Chem. Rev. 2015, 115, 3036-3140.

(51) Chen, Y.-C.; Chou, H.-H.; Tsai, M. C.; Chen, S.-Y.; Lin, J. T.; Yao, C.-F.; Chen, K. Thieno[3,4-b]thiophene-based organic dyes for dye-sensitized solar cells. Chem.-Eur. J. 2012, 18, 5430-5437.

(52) Hara, K.; Sato, T.; Katoh, R.; Furube, A.; Yoshihara, T.; Murai, M.; Kurashige, M.; Ito, S.; Shinpo, A.; Suga, S.; Arakawa, H. Novel conjugated organic dyes for efficient dye-sensitized solar cells. Adv. Funct. Mater. 2005, 15, 246-252.

(53) Al-Eid, M.; Lim, S.; Park, K.-W.; Fitzpatrick, B.; Han, C.-H.; Kwak, K.; Hong, J.; Cooke, G. Facile synthesis of metal-free organic dyes featuring a thienylethynyl spacer for dye sensitized solar cells. Dyes Pigm. 2014, 104, 197-203.

(54) Hagberg, D. P.; Edvinsson, T.; Marinado, T.; Boschloo, G.; Hagfeldt, A.; Sun, L. A novel organic chromophore for dye-sensitized nanostructured solar cells. Chem. Commun. 2006, 21, 2245-2247.

(55) Haid, S.; Marszalek, M.; Mishra, A.; Wielopolski, M.; Teuscher, J.; Moser, J.-E.; Humphry-Baker, R.; Zakeeruddin, S. M.; Grätzel, M.; Bäuerle, P. Significant improvement of dye-sensitized solar cell performance by small structural modification in $\pi$-conjugated Donor-Acceptor dyes. Adv. Funct. Mater. 2012, 22, 1291-1302.

(56) Zhang, L.; Cole, J. M. Anchoring groups for dye-sensitized solar cells. ACS Appl. Mater. Interfaces 2015, 7, 3427-3455.

(57) Liu, B.; Li, W.; Wang, B.; Li, X.; Liu, Q.; Naruta, Y.; Zhu, W. Influence of different anchoring groups in indoline dyes for dyesensitized solar cells: Electron injection, impedance and charge recombination. J. Power Sources 2013, 234, 139-146.

(58) Raposo, M. M. M.; Herbivo, C.; Hugues, V.; Clermont, G.; Castro, M. C. R.; Comel, A.; Blanchard-Desce, M. Synthesis, fluorescence, and two-photon absorption properties of push-pull 5arylthieno[3,2-b]thiophene derivatives. Eur. J. Org. Chem. 2016, 2016, $5263-5273$

(59) Fernandes, S. S. M.; Castro, M. C. R.; Mesquita, I.; Andrade, L.; Mendes, A.; Raposo, M. M. M. Synthesis and characterization of novel thieno[3,2-b] thiophene based metal-free organic dyes with different heteroaromatic donor moieties as sensitizers for dye-sensitized solar cells. Dyes Pigm. 2017, 136, 46-53.

(60) Cardona, C. M.; Li, W.; Kaifer, A. E.; Stockdale, D.; Bazan, G. C. Electrochemical considerations for determining absolute frontier orbital energy levels of conjugated polymers for solar cell applications. Adv. Mater. 2011, 23, 2367-2371.

(61) Hagfeldt, A.; Graetzel, M. Light-induced redox reactions in nanocrystalline systems. Chem. Rev. 1995, 95, 49-68.

(62) Katoh, R.; Furube, A.; Yoshihara, T.; Hara, K.; Fujihashi, G.; Takano, S.; Murata, S.; Arakawa, H.; Tachiya, M. Efficiencies of electron injection from excited $\mathrm{N} 3$ dye into nanocrystalline semiconductor $\left(\mathrm{ZrO}_{2}, \mathrm{TiO}_{2}, \mathrm{ZnO}, \mathrm{Nb}_{2} \mathrm{O}_{5}, \mathrm{SnO}_{2}, \mathrm{In}_{2} \mathrm{O}_{3}\right)$ films. J. Phys. Chem. B 2004, 108, 4818-4822.

(63) Ponseca, C. S.; Chábera, P.; Uhlig, J.; Persson, P.; Sundström, V. Ultrafast Electron dynamics in solar energy conversion. Chem. Rev. 2017, 117, 10940-11024.

(64) Boschloo, G.; Hagfeldt, A. Characteristics of the iodide/triiodide redox mediator in dye-sensitized solar cells. Acc. Chem. Res. 2009, 42, $1819-1826$.

(65) Wan, Z.; Jia, C.; Zhang, J.; Duan, Y.; Lin, Y.; Shi, Y. Triphenylamine-based starburst dyes with carbazole and phenothiazine antennas for dye-sensitized solar cells. J. Power Sources 2012, 199, 426-431.

(66) Wan, Z.; Jia, C.; Duan, Y.; Zhang, J.; Lin, Y.; Shi, Y. Effects of different acceptors in phenothiazine-triphenylamine dyes on the 
optical, electrochemical, and photovoltaic properties. Dyes Pigm. 2012, 94, 150-155.

(67) Hagfeldt, A.; Grätzel, M. Molecular photovoltaics. Acc. Chem. Res. 2000, 33, 269-277.

(68) Tian, H.; Yang, X.; Chen, R.; Pan, Y.; Li, L.; Hagfeldt, A.; Sun, L. Phenothiazine derivatives for efficient organic dye-sensitized solar cells. Chem. Commun. 2007, 36, 3741-3743.

(69) Wan, Z.; Jia, C.; Wang, Y.; Yao, X. A strategy to boost the efficiency of rhodanine electron acceptor for organic dye: from nonconjugation to conjugation. ACS Appl. Mater. Interfaces 2017, 9, 25225-25231.

(70) Wang, P.; Klein, C.; Humphry-Baker, R.; Zakeeruddin, S. M.; Grätzel, M. A high molar extinction coefficient sensitizer for stable dye-sensitized solar cells. J. Am. Chem. Soc. 2005, 127, 808-809.

(71) Benkö, G.; Kallioinen, J.; Korppi-Tommola, J. E. I.; Yartsev, A. P.; Sundström, V. Photoinduced ultrafast dye-to-semiconductor electron injection from nonthermalized and thermalized donor states. J. Am. Chem. Soc. 2002, 124, 489-493.

(72) El-Zohry, A. M.; Roca-Sanjuán, D.; Zietz, B. Ultrafast twisting of the indoline donor unit utilized in solar cell dyes: experimental and theoretical studies. J. Phys. Chem. C 2015, 119, 2249-2259.

(73) Horng, M. L.; Gardecki, J. A.; Papazyan, A.; Maroncelli, M. Subpicosecond measurements of polar solvation dynamics: coumarin 153 revisited. J. Phys. Chem. 1995, 99, 17311-17337.

(74) El-Zohry, A. M.; Zietz, B. Concentration and solvent effects on the excited state dynamics of the solar cell dye d149: the special role of protons. J. Phys. Chem. C 2013, 117, 6544-6553.

(75) Zietz, B.; Gabrielsson, E.; Johansson, V.; El-Zohry, A. M.; Sun, L.; Kloo, L. Photoisomerization of the cyanoacrylic acid acceptor group-a potential problem for organic dyes in solar cells. Phys. Chem. Chem. Phys. 2014, 16, 2251-2255.

(76) Burrows, H. D.; Greatorex, D.; Kemp, T. J. Solute radical cation yields in the pulse radiolysis of solutions of aromatic amines in chlorinated hydrocarbons. J. Phys. Chem. 1972, 76, 20-26.

(77) Meister, M.; Baumeier, B.; Pschirer, N.; Sens, R.; Bruder, I.; Laquai, F.; Andrienko, D.; Howard, I. A. Observing charge dynamics in surface reactions by time-resolved stark effects. J. Phys. Chem. C 2013, 117, 9171-9177.

(78) Cabanillas-Gonzalez, J.; Virgili, T.; Gambetta, A.; Lanzani, G.; Anthopoulos, T. D.; de Leeuw, D. M. Photoinduced transient stark spectroscopy in organic semiconductors: a method for charge mobility determination in the picosecond regime. Phys. Rev. Lett. 2006, 96, 106601.

(79) Miertuš, S.; Scrocco, E.; Tomasi, J. Electrostatic interaction of a solute with a continuum. A direct utilizaion of $\mathrm{AB}$ initio molecular potentials for the prevision of solvent effects. Chem. Phys. 1981, 55, $117-129$.

(80) Tomasi, J.; Mennucci, B.; Cammi, R. Quantum mechanical continuum solvation models. Chem. Rev. 2005, 105, 2999-3094.

(81) Pandey, L.; Doiron, C.; Sears, J. S.; Brédas, J.-L. Lowest excited states and optical absorption spectra of donor-acceptor copolymers for organic photovoltaics: a new picture emerging from tuned longrange corrected density functionals. Phys. Chem. Chem. Phys. 2012, 14, $14243-14248$.

(82) Grätzel, M. Photoelectrochemical cells. Nature 2001, 414, 338344.

(83) Zhang, G.; Bai, Y.; Li, R.; Shi, D.; Wenger, S.; Zakeeruddin, S. M.; Grätzel, M.; Wang, P. Employ a bisthienothiophene linker to construct an organic chromophore for efficient and stable dyesensitized solar cells. Energy Environ. Sci. 2009, 2, 92-95.

(84) Kubin, R. F.; Fletcher, A. N. Fluorescence quantum yields of some rhodamine dyes. J. Lumin. 1982, 27, 455-462.

(85) Becke, A. D. Density-functional thermochemistry. III. The role of exact exchange. J. Chem. Phys. 1993, 98, 5648-5652.

(86) Lee, C.; Yang, W.; Parr, R. G. Development of the Colle-Salvetti correlation-energy formula into a functional of the electron density. Phys. Rev. B: Condens. Matter Mater. Phys. 1988, 37, 785-789.

(87) Oum, K.; Lohse, P. W.; Klein, J. R.; Flender, O.; Scholz, M.; Hagfeldt, A.; Boschloo, G.; Lenzer, T. Photoinduced ultrafast dynamics of the triphenylamine-based organic sensitizer D35 on $\mathrm{TiO}_{2}, \mathrm{ZrO}_{2}$ and in acetonitrile. Phys. Chem. Chem. Phys. 2013, 15, 3906-3916.

(88) Yanai, T.; Tew, D. P.; Handy, N. C. A new hybrid exchangecorrelation functional using the Coulomb-attenuating method (CAMB3LYP). Chem. Phys. Lett. 2004, 393, 51-57.

(89) Schmidt, M. W.; Baldridge, K. K.; Boatz, J. A.; Elbert, S. T.; Gordon, M. S.; Jensen, J. H.; Koseki, S.; Matsunaga, N.; Nguyen, K. A.; $\mathrm{Su}$, S.; Windus, T. L.; Dupuis, M.; Montgomery, J. A. General atomic and molecular electronic structure system. J. Comput. Chem. 1993, 14, 1347-1363.

(90) Pina, J.; Queiroz, M.-J. R. P.; Seixas de Melo, J. Effect of substitution on the ultrafast deactivation of the excited state of benzo[b]thiophene-arylamines. Photochem. Photobiol. Sci. 2016, 15, 1029-1038.

(91) Snellenburg, J. J.; Laptenok, S. P.; Seger, R.; Mullen, K. M.; van Stokkum, I. H. M. Glotaran: A java-based graphical user interface for the R package TIMP. J. Stat. Software 2012, 49, 22.

(92) Pina, J.; Seixas de Melo, J.; Burrows, H. D.; Maçanita, A. L.; Galbrecht, F.; Bünnagel, T.; Scherf, U. Alternating binaphthylthiophene copolymers: synthesis, spectroscopy, and photophysics and their relevance to the question of energy migration versus conformational relaxation. Macromolecules 2009, 42, 1710-1719.

(93) Striker, G.; Subramaniam, V.; Seidel, C. A. M.; Volkmer, A. Photochromicity and fluorescence lifetimes of green fluorescent protein. J. Phys. Chem. B 1999, 103, 8612-8617. 